\title{
Transfusional Iron Overload in Sickle Cell Anemia
}

\section{Relationship between Liver Iron, Magnetic Resonance Imaging Findings, and Hepatic Fibrosis}

\author{
SHARADA A. SARNAIK, ${ }^{a}$ CHUNG-HO CHANG, AND \\ RAMIRO HERNANDEZ \\ Wayne State University School of Medicine \\ Children's Hospital of Michigan \\ Detroit, Michigan \\ and \\ Mott Children's Hospital \\ Ann Arbor, Michigan
}

Multiple exposures to blood transfusions can result in significant hepatic toxicity from viral infections and iron overload. 'This toxicity is cumulative and can be the limiting factor in an otherwise successful prophylactic transfusion regimen for specific complications of sickle cell disease which are both recurrent and life-threatening. This study was undertaken to determine the extent of hepatotoxicity in such patients and the value of magnetic resonance imaging (MRI) in its evaluation.

\section{METHODS}

Subjects of this study were 17 individuals with SS hemoglobinopathy, whose ages ranged from 30 to 231 months (median 125). There were 12 males; indications for transfusions were splenic sequestration and stroke. Patients received one to two units of blood every three to four weeks as previously described. ${ }^{2}$ After obtaining informed consent, all subjects had percutaneous needle liver biopsies. Iron was quantitated by atomic flame spectrophotometry, and reported in micrograms per gram dry weight.

TABLE 1. Statistical Correlations: MRI Findings

\begin{tabular}{ccccccc}
\hline & & & Liver/Muscle & T1/T2 & Liver & Serum \\
& Liver Pathologya & SIR & Liver & FF & Ferritin \\
\hline \multirow{3}{*}{ Duration of transfusion } & $r$ & 0.72 & 0.58 & 0.002 & 0.63 & 0.82 \\
& $\mathrm{p}$ & $<0.001$ & $<0.002$ & NS $^{b}$ & $<0.01$ & $<0.001$ \\
& $n$ & 17 & 15 & 15 & 17 & 17 \\
\hline
\end{tabular}

${ }^{\circ}$ Summated pathologic score.

${ }^{b} \mathrm{NS}$ is not significant.

address correspondence to Dr. Sarnaik at The Children's Hospital of Michigan, Comprehensive Sickle Cell Center, 3901 Beaubieu Boulevard, Detroit, Michigan 48201. 
TABLE 2. Pathologic Changes in Liver Biopsies: Severity Scores

\begin{tabular}{|c|c|c|c|c|c|c|}
\hline \multirow{2}{*}{$\begin{array}{c}\text { Patient } \\
\text { Number }\end{array}$} & \multicolumn{2}{|c|}{ Hemosiderosis } & \multicolumn{2}{|c|}{ Portal } & \multirow{2}{*}{$\begin{array}{l}\text { Hepatocyte } \\
\text { Swelling }\end{array}$} & \multirow{2}{*}{$\begin{array}{l}\text { Total } \\
\text { Score }\end{array}$} \\
\hline & Hepatocyte & Kupffer & Fibrosis & Infiltrates & & \\
\hline 1 & 3 & 4 & NA & NA & 1 & NA \\
\hline 2 & 3 & 2.5 & 1 & 0 & 1 & 7.5 \\
\hline 3 & 3 & 3 & $i$ & 1 & 1 & 9.0 \\
\hline 4 & 3.5 & 4 & 2 & 3 & 0 & 12.5 \\
\hline 5 & 2.5 & 3.5 & 3 & 2 & 2 & 13.0 \\
\hline 6 & 3 & 4 & 1 & 1 & 1 & 10.0 \\
\hline 7 & 2 & 2.5 & 0 & 0 & 0 & 4.5 \\
\hline 8 & 3 & 3 & 3 & 1 & 2 & 12.0 \\
\hline 9 & 1 & 1 & 0 & 1 & 2 & 5.0 \\
\hline 10 & 2.5 & 3 & 1 & 0 & 0 & 6.5 \\
\hline 11 & 3 & 4 & 2 & 2 & 2 & 13.0 \\
\hline 12 & 2.5 & 2 & 0 & 1 & 1 & 6.5 \\
\hline 13 & 2 & 3 & 1 & 2 & 2 & 10.0 \\
\hline 14 & 1 & 1 & 0 & 0 & 1 & 3.0 \\
\hline 15 & 3 & 4 & 2 & 1 & i & 11.0 \\
\hline 16 & 1 & 2 & 0 & 0 & 1 & 4.0 \\
\hline 17 & 1 & 1 & 0 & 0 & i & 3.0 \\
\hline
\end{tabular}

Biopsy specimens were scored blindly for degree of hemosiderosis, fibrosis, and hepatocyte swelling by a single pathologist. MRI scans were performed at a mean time to biopsy of 1.9 months, using a Diasonics MT/S superconductive magnet. Liver to muscle signal intensity ratios (SIR) were calculated. Serum ferritin was measured with a mean time to biopsy of 3 months, using enzyme immunoassay kits (Hybridtech).

\section{RESULTS}

Transfusion duration significantly correlated with liver iron, serum ferritin, SIR, and summated pathologic score. There was, however, no correlation with T1 or T2 relaxation times or their ratio (TABLE 1). Although there was good correlation between SIR and liver iron $(r=0.58, \mathrm{p}<0.002)$, SIR could not differentiate between liver irons of 150 and 400 micrograms/mg. Histopathology showed significant hemosiderosis in all patients; portal fibrosis indicating various degrees of cirrhosis was seen in more than half the cases (TABLE 2).

\section{DISCUSSION}

Liver damage reflected by a pathologic score could be significantly related to transfusion duration, indicating cumulative hepatitis and iron loading. MRI was not adequate to quantitate liver iron, and may not be a good tool for the long-term follow-up of patients undergoing chelation therapy. Patients with sickle cell anemia who are on prophylactic transfusion regimens are at risk for developing severe liver damage. Two patients in this series did, in fact, have cirrhotic changes (grade 3 fibrosis). The benefits of transfusion regimens must thus be weighed against these demonstrated risks, and clinicians must make decisions to discontinue transfusions 
based on the severity of demonstrated toxicity. The risks of the "gold standard" of liver biopsy obviate its routine use, and newer, non-invasive technology such as MRI should continue to be evaluated for its usefulness in evaluating liver toxicity.

\section{REFERENCES}

1. Pastore, G., N. Tannoia, L. angarano, L. Monno, T. Santanionio, A. PietrapertoSA, G. Malcangi, A. Putignano \& O. Schiraldi. 1983. Chronic viral hepatitis in thalassemic liver disease. Vox Sang. 44: 14-24.

2. Sarnaik, S., D. Soorya, J. Kim, Y. Ravindranath \& J. Lusher. 1979. Periodic transfusion for sickle cell anemia and CNS infarction. Am. J. Dis. Child. 133: 12541257. 